\title{
PREPRINT
}

\section{Severity assessment in the Nicotiana tabacum-Xylella fastidiosa subsp. pauca pathosystem: design and inter-laboratory validation of a standard area diagram}

Willian Eduardo Lino Pereira ${ }^{1,28}$, Sheila Maria Pereira de Andrade ${ }^{38}$, Emerson M. Del Ponte $^{3}$, Mariana Bossi Esteves ${ }^{4}$, Maria Cristina Canale ${ }^{5}$, Marco Aurélio Takita ${ }^{1}$, Helvécio Della Coletta-Filho ${ }^{1}$, Alessandra Alves De Souza $^{1 *}$

\footnotetext{
${ }^{1}$ Centro de Citricultura Sylvio Moreira, Instituto Agronômico de Campinas (IAC), Cordeirópolis, 13490-000, São Paulo, Brazil

${ }^{2}$ Universidade Estadual de Campinas , Campinas, 13083-97, São Paulo, SP, Brazil

${ }^{3}$ Departamento de Fitopatologia, Universidade Federal de Viçosa (UFV), 36470-900 Viçosa, MG, Brazil

${ }^{4}$ Departamento de Entomologia e Acarologia, Escola Superior de Agricultura "Luiz de Queiroz" (ESALQ), Universidade de São Paulo, Piracicaba, 13418-900 São Paulo, SP, Brazil

${ }^{5}$ Empresa de Pesquisa Agropecuária e Extensão Rural de Santa Catarina (Epagri), 89803-904, Chapecó, SC, Brazil

${ }^{\mathrm{x}}$ These authors contributed equally to the work

*Corresponding author: Alessandra A. de Souza, e mail: desouza@ccsm.br
}

\section{Abstract}

Nicotiana tabacum, a non-natural host, is an excellent plant model for biological and functional genomics studies on plant host-Xylella fastidiosa interactions. Symptoms by X. fastidiosa subsp. pauca on tobacco have been characterized but current severity assessment method is an ordinal scale developed for symptoms on citrus. We designed a standard area diagram (SAD) to aid in the visual estimation of percent area affected (\% severity) and performed a multi-laboratory validation on tobacco cv. 'Havana inoculated with X. fastidiosa subsp. pauca. Inoculated plants were monitored over time and digital images of the symptoms were obtained. Three different softwares (APS Asses, ImageJ and Leaf Doctor) were used to segment the images and calculate \% severity. Ten true-color images composed a 10-image $\operatorname{SAD}(0.5,5,10,15,25,35,45,55,65$ and 75\%). Fifty raters at four laboratories assigned \% severity first without and then with the SAD 
on the same testing image set of 40 images following the same instructions provided by an examiner at each Laboratory. The means of \% severity by all softwares were assumed to represent the actual \% severity given the perfect agreement between them. The unaided estimates were less precise, biased towards overestimation (up to 50 percent points) and less concordant between raters. Accuracy and precision varied considerably among the raters and effect of the SAD on the overall concordance to the actual severity was dependent on the Laboratory; in all but one Laboratory, the group means of the agreement index statistically improved. The between-rater agreement improved in all Laboratories when using the SAD. The SAD may help to standardize and allow comparison across different laboratories, but care should be taken during instructions on how to discriminate symptoms that are not readily discernible as well as on how to correctly use of the SAD.

\section{Introduction}

The plant pathogenic bacterium Xylella fastidiosa is a newly emergent global threat to several perennial crops including citrus, grape, coffee, almond, oak, plum and olive (Saponari et al. 2013; Mansfield et al. 2012; Almeida et al. 2019). Whilst X. fastidiosa epidemics are spreading quickly, research on the vector- X. fastidiosa -host interactions progresses at a much slower pace. There is vast amount of information generated by novel sequencing technologies but functional genomics studies are a bottleneck because advancing the biological understanding has been constrained by operational issues (Coletta-Filho et al. 2020).

The development of Citrus Variegated Chlorosis (CVC) disease caused X. fastidiosa subsp. pauca is highly dependent on environmental conditions (Coletta-Filho et al. 2013). In sweet orange (Citrus sinensis L. Osb), the time to symptom expression 
naturally by the vector-transmitted X. fastidiosa may take longer than nine months in natural conditions (Damsteegt et al. 2006). Inoculation efficiency and length of incubation period are variable even using standard inoculation method with a highly concentrated inoculum in a controlled environment (Chang et al. 1993, Lopes et al. 2000). More than five months may be required for the expression of CVC symptoms in sweet orange under optimal conditions (Lopes et al. 2005).

Since Nicotiana tabacum was shown to host X. fastidiosa (Lopes et al. 2000), studies on comparative pathogenicity, host resistance, gene function, and effect of antimicrobials and nutritional plant responses, among others, have used tobacco as a model host (Alves et al. 2003; Andreote et al. 2006; Dandekar et al. 2012, De La Fuente et al. 2013; Francis et al. 2008; Caserta et al. 2017; Lopes et al. 2019). While inoculation methods have been tested and used for tobacco across different laboratories, the current rating system is based on ordinal scores of the severity of X.fastidiosa subsp. pauca-induced symptoms based on citrus leaves where the symptomatology is different from tobacco (Amorim et al. 1993; Muranaka et al. 2013; Caserta et al. 2017).

In phytopathometry, disease severity is defined as the proportion or percent area of the plant or plant organ affected by symptoms (Nutter et al. 2006; Madden et al. 2007). For foliar diseases that cause necrosis, associated or not with chlorosis, a percent severity value (a ratio variable), opposed to descriptive or scale-based scores, is usually the most informative variable for pathogen biology and disease epidemiology studies as well as evaluation of control methods (Bock et al. 2016). Thus far, the most used time-effective method to obtain direct estimates of percent severity, depending on the objective and scale, is through perception of colors in the visible spectrum by human raters - these should be capable of identifying the target symptoms and assigning percent values as close as possible to the "actual" severity value (Bock et al. 2020). The 
task is subjective and the accuracy (closeness to the actual value) of the visual estimates varies from person to person (Bock et al. 2016).

Standard area diagram (SAD) is a visual aid that generally, but not always, improves significantly the accuracy of the visual estimates according to results by over a hundred of validation studies (Bock et al. 2016; Del Ponte et al. 2017). Most commonly, a SAD is designed and validated for a specific disease and, occasionally, compared with existing ones (Del Ponte et al. 2017; Franceschi et al. 2020). In fact, a large and dynamic variation in the morphological features (number, size, shape and color) of lesions exist among diseases given the infinite number of interactions from the combination of groups of pathogens, plants and environment, which shape the symptomatic patterns (Lucas 2020). It is possible that the use of SAD developed for other diseases can be beneficial as long as there is a good match between the symptoms. Two versions of SAD were developed for X. fastidiosa affecting citrus leaves (Amorim et al. 1993). The pattern of the symptoms in citrus leaves are distinct from those we observe routinely for $\mathrm{X}$. fastidiosa subsp. pauca on tobacco leaves (Caserta et al. 2017).

The validation step for a SAD aims at checking whether the method improves the accuracy of the visual estimates in comparison to a check (no SAD) or any other available method (e.g. other SAD) (Del Ponte et al. 2017). For such, a sample of individuals (hereafter raters) that usually lack experience in visual estimates of severity for the target pathosystem are selected at random. These raters assign severity in a testing set, usually a subset of the digital images of symptomatic leaves with known actual severity. The number of raters should be sufficient to obtain more precise estimates of the effect, but this aspect has not been fully explored in SAD research (Del Ponte et al. 2017). Moreover, it is poorly known whether the validation results for one SAD are consistent across different groups where the testing conditions may not be the same. Only 
recently, inconsistency in accuracy of the visual estimate of severity were shown during validation of a SAD when the instructions and methodology for obtaining actual severity (different software) in the test images set differed between two laboratories (Melo et al. 2020).

The availability of a standardized method that is both cost and time effective, reliable and reproducible may be useful in studies for screening of candidate genes for resistance to $\mathrm{X}$. fastidiosa or evaluation of strains for aggressiveness. Therefore, the main objectives of this study were to develop a SAD for the tobacco-X. fastidiosa subsp. pauca pathosystem and perform an multi-laboratorial validation. A secondary objective was to compare measures of severity provided by three different software obtained by the same operator.

\section{Materials and Methods}

\section{Plant and bacterial growth and inoculations}

The 9a5c strain of X. fastidiosa subsp. pauca (Simpson et al., 2000) isolated from CVC-symptomatic sweet orange plant was cultivated on periwinkle wilt medium (PWG) (Davis et al. 1981; Hill Purcell 1995) at $28^{\circ} \mathrm{C}$. Bacterial colonies were scraped from plates and resuspended in PBS $\left(8 \mathrm{~g} / \mathrm{L} \mathrm{NaCl}, 0.2 \mathrm{~g} / \mathrm{L} \mathrm{KCl}, 1.78 \mathrm{~g} / \mathrm{L} \mathrm{Na}_{2} \mathrm{HPO}_{4} \cdot 2 \mathrm{H}_{2} \mathrm{O}\right.$, and $0.27 \mathrm{~g} / \mathrm{L}$ $\mathrm{KH}_{2} \mathrm{PO}_{4}$ at $\mathrm{pH}$ 7.4) for preparing suspensions. Inoculum concentration was standardized by both $\mathrm{OD}(0.8)$ at $600 \mathrm{~nm}$ and by number of $\mathrm{CFU} / \mathrm{mL}$ plating $10 \mathrm{X}$ serial dilutions in PW medium, to around $10^{7} \mathrm{CFU} / \mathrm{mL}$. 
Nicotiana tabacum cv. Havana plants were grown in $0.5 \mathrm{~L}$ pots filled with a commercial substrate (Plantmax Eucatex) and maintained in a greenhouse with temperatures allowed to vary from 14 to $30{ }^{\circ} \mathrm{C}$. Eighty five day-old plants were randomly selected for inoculations with the bacterial suspension and 21 with the PBS as negative control, in two independent experiments. For inoculation, a $15 \mathrm{uL}$ drop of inoculum suspension was deposited on the main stem of each $10-\mathrm{cm}$ height. The tissue was pricked through the drop few times with an entomological needle no. 2 (Supplemental Fig. 1). For the following sampling procedures, the inoculation point was marked with a colored tape as reference.

\section{Image acquisition and processing}

The plants were monitored closely after the inoculation to select leaves that best represented the symptoms at the widest range of severity as possible. The selected ones were detached from the plant and taken to the laboratory. Each leaf was scanned individually (HP Photosmart) on top of a uniform white background. The images were stored as TIFF file at a 300 dpi resolution. Of an initial set of 175 images, a subsample of 105 images were selected after quality check for the further analyses. The image files are publicly available at https://osf.io/2z8p6/.

\section{Measure of actual severity}

To obtain the actual severity, the symptomatic area needs to be discriminated from the non symptomatic one. This is currently performed using image analysis softwares that use color-transformation methods for segmentation of images obtained under 
controlled conditions (e.g. background, light, resolution) (Del Ponte et al. 2017). Here, we used two desktop and one smartphone application that allow to segment the images and calculate percent leaf area affected. The proprietary Windows-based software APS Assess (Lamari et al. 2009) is considered a gold standard in the field of phytopametry. It facilitates thresholding the entire leaf and the lesions separately using either manual or automatic procedures. ImageJ (Schneider et al. 2012) is an open source multi platform image processing software that works similarly to APS Assess. The Leaf Doctor is a plant-disease specific portable app for smartphones and tablets that allows the user to select up to eight colors using touch-screen technology to select pixels representing the symptomatic tissue (Pethybridge and Nelson 2015). Here, the same operator selected the areas of interest when thresholding the image to obtain percent severity using each of the three softwares. In Assess, the color space used was HSV in the manual panel while in ImageJ was HSB; both are alternative representations of the RGB color. To select 'Lesion' the thumber positions were defined for each software, in Asses the lower was 31 and upper ranged from 95 to 105 depending on disease severity. For ImageJ the lower ranged from 40-46 and upper was 0 . The measures were compared among the different software using descriptive statistics and concordance analysis (details in the agreement section).

\section{SAD design}

Because of the relatively high upper limit of measured severity $(84 \%)$ in the sample, a 10-image true-color set with the reference severities spaced at approximately linear increments was designed based on guidelines for best practices (Del Ponte et al. 2017). This 'amended-linear' percent scale (Liu et al. 2019) of incremental severity results from placing additional diagrams from lowest to $\sim 10$ to $15 \%$ severity to minimize 
overestimation that is common in that range for some kinds of symptomatic patterns but also the natural lower bound (Bock et al. 2010; Schwanck and Del Ponte 2014). Our SAD was designed with four images from the lowest to $15 \%$ severity and six additional images were spaced at a fixed 10\% interval (Fig. 1). The images of the leaves representing each reference severity were chosen based on criteria such as leaf integrity, representativeness and consistency of symptoms.
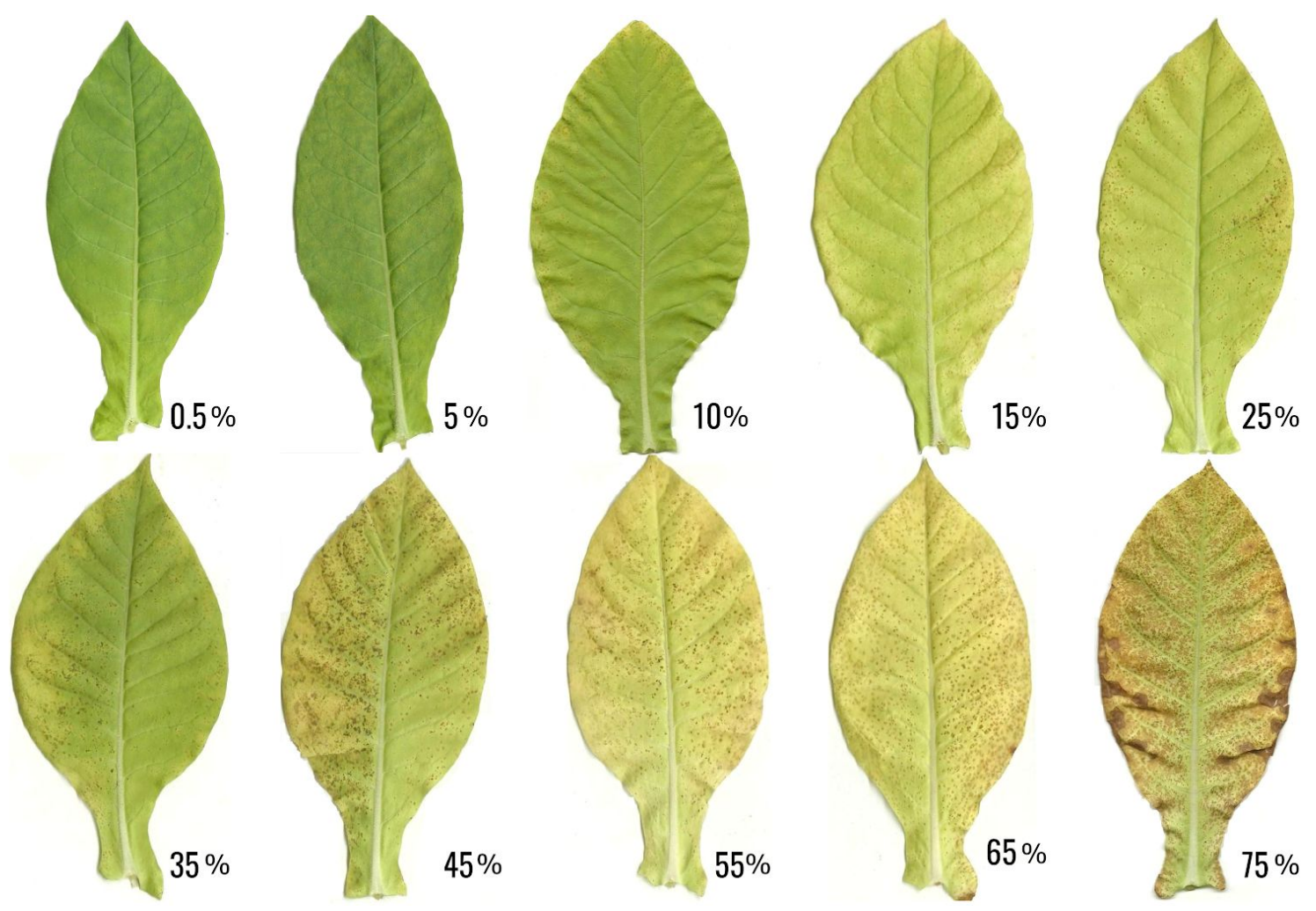

Fig. 1 Standard area diagram for the severity of symptoms caused by the colonization of Xylella fastidiosa subsp. pauca from inoculations of $15 \mathrm{uL}$ drop of a bacterial suspension concentrated at $10^{7} \mathrm{CFU} / \mathrm{mL}$ at the base of five days-old Nicotiana tabacum plants 


\section{Validation of the SAD}

A subset of 40 images (not used in any reference of the SAD) with severity values uniformly distributed with increments spaced around five percent points from each other. A multi-laboratory validation was performed to check whether the proposed method (SAD + instruction) leads to consistent and reproducible results across groups of users. Differently from the work by Melo et al. (2020), we used the same set of reference images across the Laboratories and provided standard instructions in a slide presentation. At each Laboratory, one examiner was responsible for testing the raters and take the following decisions: a) select the raters; b) use the more convenient and available image projection setting (wall projection, computer screen); and 3) define the oral explanation to complement the instructions presented textually and graphically in a slide presentation. A more detailed summary of the conditions at each Laboratory is presented (Table 1).

The validation was completed in three sessions. Firstly, the examiners provided written standardized instructions shared previously in a Google Slide presentation with all four examiners. The raters received instructions on how to recognize and discriminate the symptomatic X. fastidiosa-infected tissues from the non-symptomatic ones supported by true-color images of symptomatic leaves. In this step the raters did not have access to any of the images displaying an actual severity value. Secondly, each image of the validation set was presented to the raters during a fixed time, in seconds (Table 1).

The raters recorded the perceived percent area of the leaf affected by the symptoms. The values were written down in a paper spreadsheet and were considered the unaided estimates. Finally, after a short break of five minutes, the same raters received a photo paper copy of the true-colored SAD. The examiners orally 
complemented the instructions on how to use the SAD during the assessment displayed in a Google Slide presentation. The same images of the validation set were displayed again and raters reassigned severity now aided by the SAD on a blank spreadsheet.

Table 1 Characteristics of the test setup in four Laboratories where a standard area diagram of severity of symptoms on tobacco leaves inoculated with Xylella fastidiosa subsp. pauca was validated on a test set of 40 leaves

\begin{tabular}{|c|c|c|c|c|c|}
\hline Lab Code ${ }^{1}$ & $\begin{array}{l}\text { No. of } \\
\text { raters }\end{array}$ & $\begin{array}{l}\text { Test assessment } \\
\text { setting }\end{array}$ & $\begin{array}{l}\text { Image } \\
\text { projection }\end{array}$ & $\begin{array}{l}\text { time/ } \\
\text { image }\end{array}$ & $\begin{array}{l}\text { Group composition by } \\
\text { academic training level }\end{array}$ \\
\hline$A$ & 14 & Individual & $\begin{array}{l}\text { Computer } \\
\text { screen }\end{array}$ & $15-25 s$ & $\begin{array}{l}1 \text { undergraduate student } \\
8 \text { researchers } \\
5 \text { technicians }\end{array}$ \\
\hline B & 10 & Individual & $\begin{array}{l}\text { Computer } \\
\text { screen }\end{array}$ & $25 s$ & $\begin{array}{l}4 \text { undergraduates students } \\
5 \text { graduate students in } \\
\text { entomology } \\
1 \text { researcher entomology }\end{array}$ \\
\hline C & 14 & Group & $\begin{array}{l}\text { White wall and } \\
\text { computer } \\
\text { screen }\end{array}$ & $30 \mathrm{~s}$ & $\begin{array}{l}7 \text { undergraduate student } \\
4 \text { graduate students in biology } \\
3 \text { researchers }\end{array}$ \\
\hline$D$ & 12 & $\begin{array}{l}\text { Individual at } \\
\text { scheduled times }\end{array}$ & $\begin{array}{l}\text { Computer } \\
\text { screen }\end{array}$ & $20-30 s$ & $\begin{array}{l}11 \text { graduate students plant } \\
\text { pathology } \\
1 \text { researcher veterinary }\end{array}$ \\
\hline
\end{tabular}

$\overline{1 \text { The Laboratories where located at the institutions as fully described in the authorship and designated }}$ here with the acronym. $A=$ Epagri; $B=E S A L Q ; C=I A C ; D=U F V$.

For data visualization and analysis, scatter plots with a smoothed trend line were constructed to depict the relationship between the software measures and the deviations (estimate minus the software measures) of the visual estimates for each image, both unaided and aided by the SAD. 


\section{Agreement metrics for individual raters}

Measures of agreement are commonly used to quantify the degree of closeness between readings (e.g. estimate and a reference), which are often defined as a function of absolute distances between readings. The Lin's Concordance Correlation Coefficient (Lin's CCC) is a scaled index for assessing such differences that has been recommended and widely used more recently in SAD research (Madden et al. 2007; Del Ponte et al. 2017). In brief, Lin's CCC allows to evaluate the degree to which the estimates fell on the line of concordance $\left(45^{\circ}\right.$, where slope $=1$, intercept $\left.=0\right)$. The overall agreement $\left(\rho_{\mathrm{c}}\right)$ is a product of precision (Pearson's $r$ ) and overall bias $\left(C_{b}\right)$, calculated from systematic bias $(u)$ and constant bias $(\mu)$. Deviation of $\rho_{c}, r, C_{b}$ and $u$ from 1 and $\mu$ from zero indicates loss of precision and loss of agreement. Analyses of the Lin's CCC statistics were conducted for the estimates obtained both without the SAD and with the SAD for the same rater. The calculations were performed in the $\mathrm{R}$ statistical environment using the epi.ccc function of the irr package (Gamer et al. 2019).

The individual rater CCC statistics were visualized using scatter plots for the relationship between $C_{b}$ and $r$ with dots colored by $\rho_{c}$. In addition, a slope graph depicted the change (dotted line) in the concordance coefficient between the unaided and $\mathrm{SAD}$-aided estimates for each rater.

\section{Interrater reliability}

The agreement between the observers, all raters combined or grouped by Laboratory, was assessed based on the overall concordance correlation (OCCC), an improvement of the CCC for multiple raters (Barnhart et al. 2002) and the intraclass correlation coefficient (ICC). Various ICCs can be defined by forming appropriate ratios of variances 
(Shrout and Fleiss, 1979) for assessing agreement between multiple observers where none of them is treated as reference (Barnhart et al. 2007). We calculated the coefficient according to the convention by Shrout and Fleiss (1979), the ICC2 $(2,1)$. We used the ICC function (lmer parameter as TRUE) of the psych R package (R Core team 2020) to obtain the estimates and the confidence limits. Our decisions were: 1) a two-way random effects model: subjects and raters randomly chosen from a larger pool; 2) single rater: measure of a single rater and not the average of $\mathrm{k}$ raters is performed, 3) absolute agreement: agreement between two raters is of interest including systematic errors and random residual errors. The OCCC was calculated using the epi.occc function of the epiR package (Stevenson et al. 2019) of R. Because the ICC2 and OCCC gave very similar estimates (data not shown) we present only the ICC2 results.

\section{SAD and Laboratory effect on accuracy of visual estimates}

We modelled the three main statistics of the Lin's concordance analysis $\left(\rho_{\mathrm{c}}, r\right.$ and $\left.C_{\mathrm{b}}\right)$ as a function of the covariates by fitting a generalized linear mixed model with a beta family and logit function. The logit link ensures positive fitted values with 1 as upper bound, which was the case (in our study) of the CCC scaled index. The fixed covariates were method (unaided and aided) and laboratory (categorical with four levels). The interaction term was method $\mathrm{x}$ laboratory. To incorporate the dependences among estimates by the same rater, we used raters as random intercept. The package glmmTBM (Brooks et al. 2017) in the R software (R Core team 2020) was used to fit the GLMMs. Model assumptions were verified by plotting residuals versus fitted values, versus each covariate in the model versus each covariate not in the model. The emmeans function of 
the emmeans package in $\mathrm{R}$ was used to calculate the marginal means and respective lower and upper 95\% confidence interval.

\section{$X$. fastidiosa detection and quantification}

Bacteria detection and quantification was done by real time quantitative PCR (qPCR). Firstly, total DNA was purified based on CTAB-based methodology (Murray and Thompson, 1980) and standardized at $250 \mathrm{ng} / \mu \mathrm{L}$. The qPCR was performed by using set of oligos published by Oliveira et al., (2002) in reactions of $25 \mu \mathrm{L}$ vol containing $1 \mathrm{X}$ HOT FIREPol@ TaqMan PCR Master Mix (Solis BioDyne - Tartu, Estonia) in a ABI PRISM 7500 Sequence Detector System (Applied Biosystems, Waltham, MA, USA). The X. fastidiosa quantification (Log Cells / g tissue) was performed using the standard curve $[y=$ -3.0153x (Log Cells $)+36.38]\left(\mathrm{R}^{2}=0.9901\right)$ obtained by correlation between 10X serial dilution of genomic DNA of $\mathrm{X}$. fastidiosa (9a5c strain) and mean values of $\mathrm{C}_{\mathrm{T}}$ (cycle threshold) from qPCR.

\section{Results}

\section{Disease symptoms and threshold for symptom expression}

The initial symptoms appeared as small necrotic spots (Fig. 2A,B). The earliest symptoms appeared at 25 DAI in three plants, but most of the plants $(n=43)$ were symptomatic at 50 DAI. Thirty percent of the inoculated leaves did not show symptoms (Fig. 2C) and a range of severity was found, with some leaves exhibiting extensive severity (Fig. 2D). The successfully X. fastidiosa-infected plants exhibited Ct values ranging from 22 to 34 . The growth of X. fastidiosa into tobacco plants reached a concentration as high as $10^{8}$ cells $\mathrm{g}^{-1}$ tissue concentration at $80 \mathrm{DAI}$, remaining constant up to $100 \mathrm{DAI}$. Bacteria were 
detected in the asymptomatic leaves at concentration averaging $4 \times 10^{4}$ cells $\mathrm{g}^{-1}$ tissue, statistically different from the symptomatic leaves, but not differing between asymptomatic leaves collected at 25 or 95 DAI ( $t$ test, $P>0.05)$. Therefore, the threshold of X. fastidiosa 9a5c strain for symptoms expression in tobacco plants must be higher than $10^{4}$ cells /g (Fig. 2E).
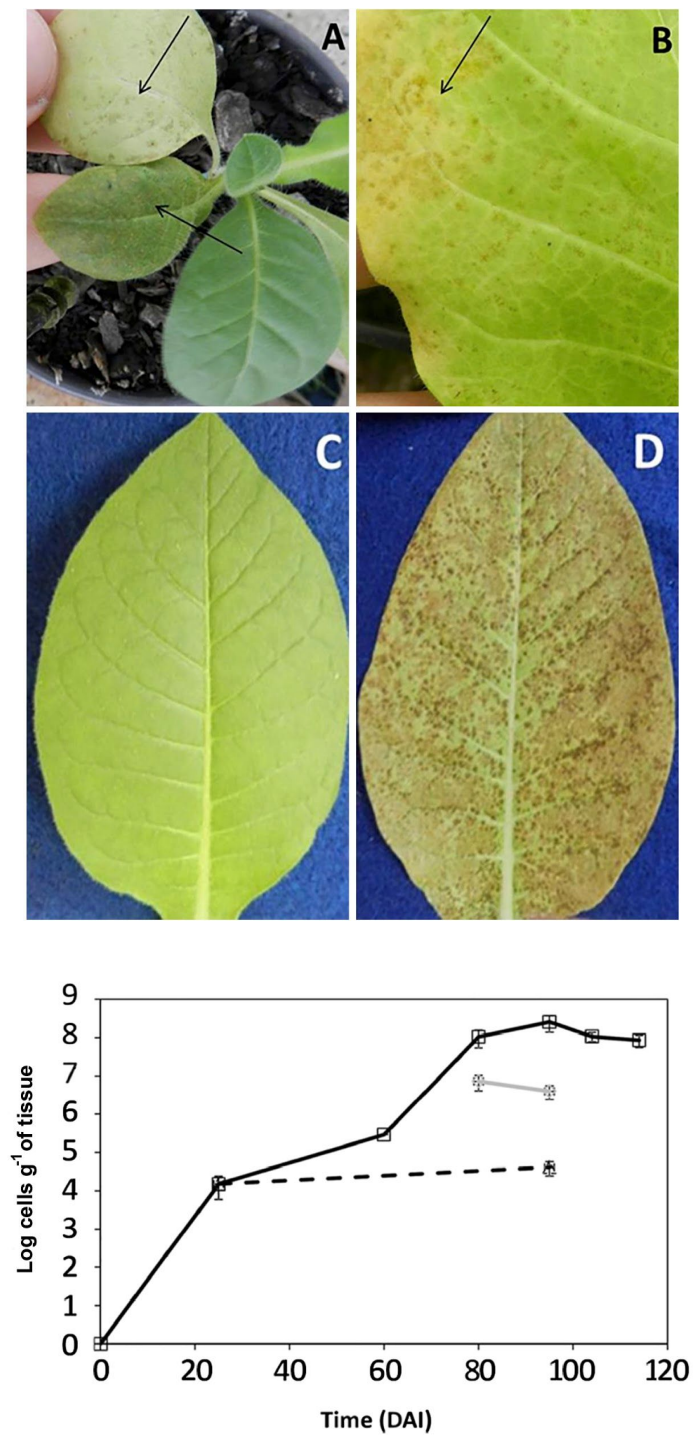

Fig. 2. Detailed view of initial symptoms caused by Xylella fastidiosa subsp. pauca on young plants (A) and a leaf (B) of Nicotiana tabacum. A suspension of $15 \mathrm{uL}\left(10^{7} \mathrm{CFU} / \mathrm{mL}\right)$ was inoculated at the base of $10-\mathrm{cm}$ height plants. Not all leaves of the inoculated plants expressed symptoms (C) but some leaves exhibited high severity, especially those close to the inoculated point. The bacteria was found in tissues of asymptomatic leaves 
(dashed line E) in $10^{4}$ cells $/ g$ of tissue even at 100 DAI. The bacterial concentration increased up to $10^{8}$ in the symptomatic plants up to 80 DAI, remaining stable afterwards (solid line E).

\section{Software measures and actual severity}

The measures of severity obtained using the three softwares strongly agreed between them. The estimates of the scaled index of agreement $\left(\rho_{c}\right)$ were $>0.99$ for all pairwise comparisons. ImageJ and Leaf Doctor agreed the most between each other (Fig. 3) with an average absolute difference of 0.5 percent points (p.p.) compared with APS Assess. For the subsequent analysis, we then assumed that the average of measures by the three softwares represents the "actual" severity. The absolute p.p. differences between measures by each software and the actual severity (overall means) fell within the range of -3 to 3 (Fig. 3D-E). The widest 95\% CI of the agreement limits (Bland and Altman 1983) was -3.25 to 2.57 when APS Assess was compared with the actual severity (Fig. 3E).

\section{Error of the estimates}

The error of the estimates for all raters combined ( $n=2,000$ estimates) were more often positive (smooth line above zero) suggesting a general tendency of overestimation across the entire range of actual severity regardless of the method (Fig. 4A). The use of the SAD allowed to reduce the errors but still considerable positive deviations remained especially at lower end and up to $20 \%$ actual severity (Fig. 4B). The global average of the differences were reduced from 10.6 to 5.5 p.p. when using the SAD compared with the unaided estimates. 

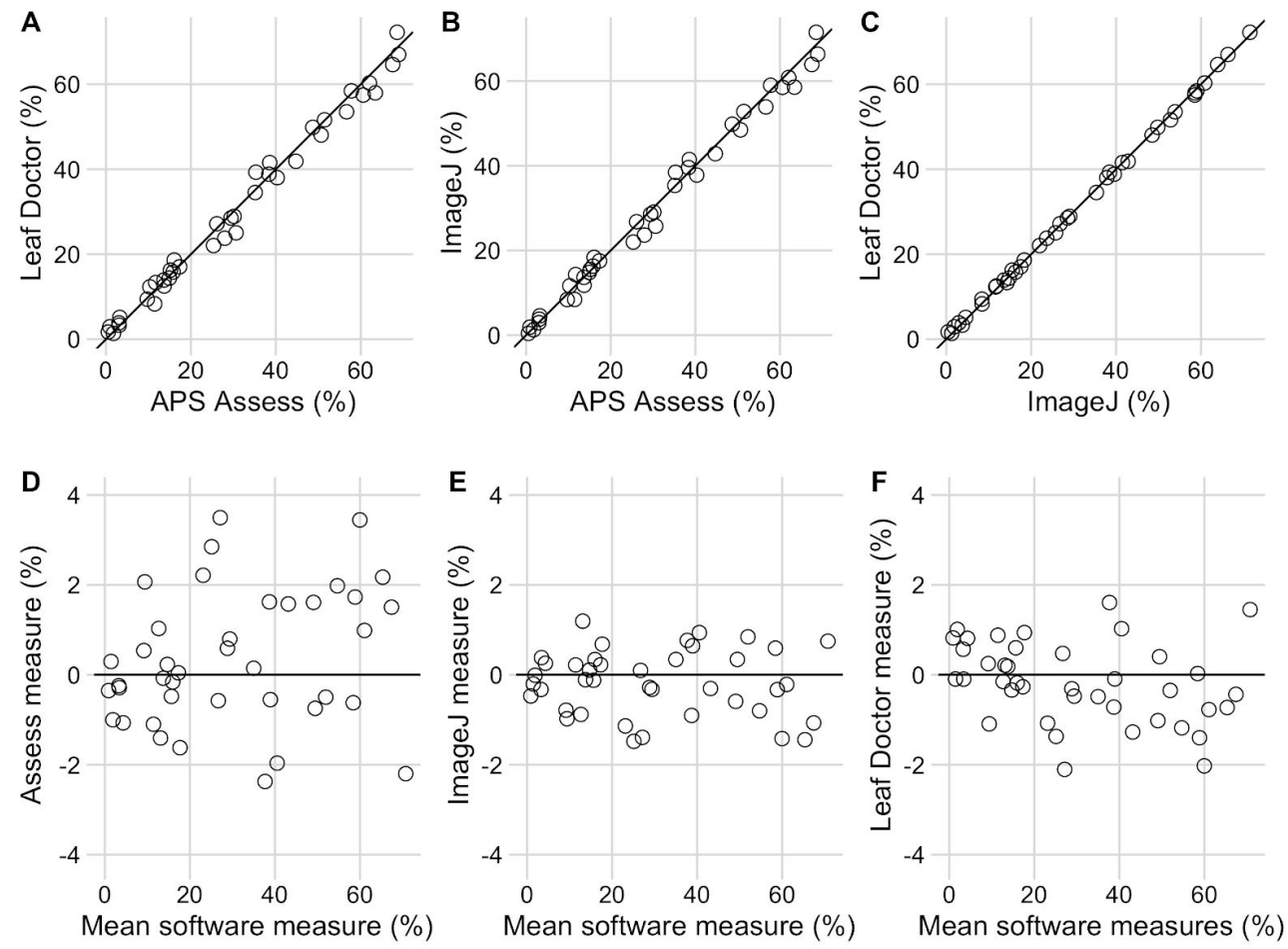

Fig. 3 Relationships of measures of percent severity of symptoms caused by Xylella fastidiosa subsp. pauca on Nicotiana tobacco leaves obtained using three different image processing software (A-C; the solid line represents perfect concordance). The error of the measure by each software was plotted against the mean of the three measures (D-F; the horizontal solid line represents the no error).

\section{Effect of the SAD and Laboratory}

Mixed model results showed that the effect of the method on the Lin's CCC statistics was dependent on the laboratory given the significance of the interaction term $(P<0.001)$. The predicted marginal means for the Lin's concordance coefficients conditioned to each level of laboratory were between 0.63 and 0.78 for the unaided estimates and between 0.82 and 0.89 for the SAD-aided estimates (Fig. 5). A stronger effect of the SAD use on the overall concordance was estimated for the Laboratories C and D where the mean gain in overall accuracy were +0.22 and +0.14 , respectively (Fig. 5). The effect of 
the SAD was moderate or minimal in Laboratories A and B, respectively. The means of the estimated differences in generalized bias and precision statistics were not deemed significant at $5 \%$ probability for Laboratory B and significant at the same probability for precision in Laboratory A (Table 2).
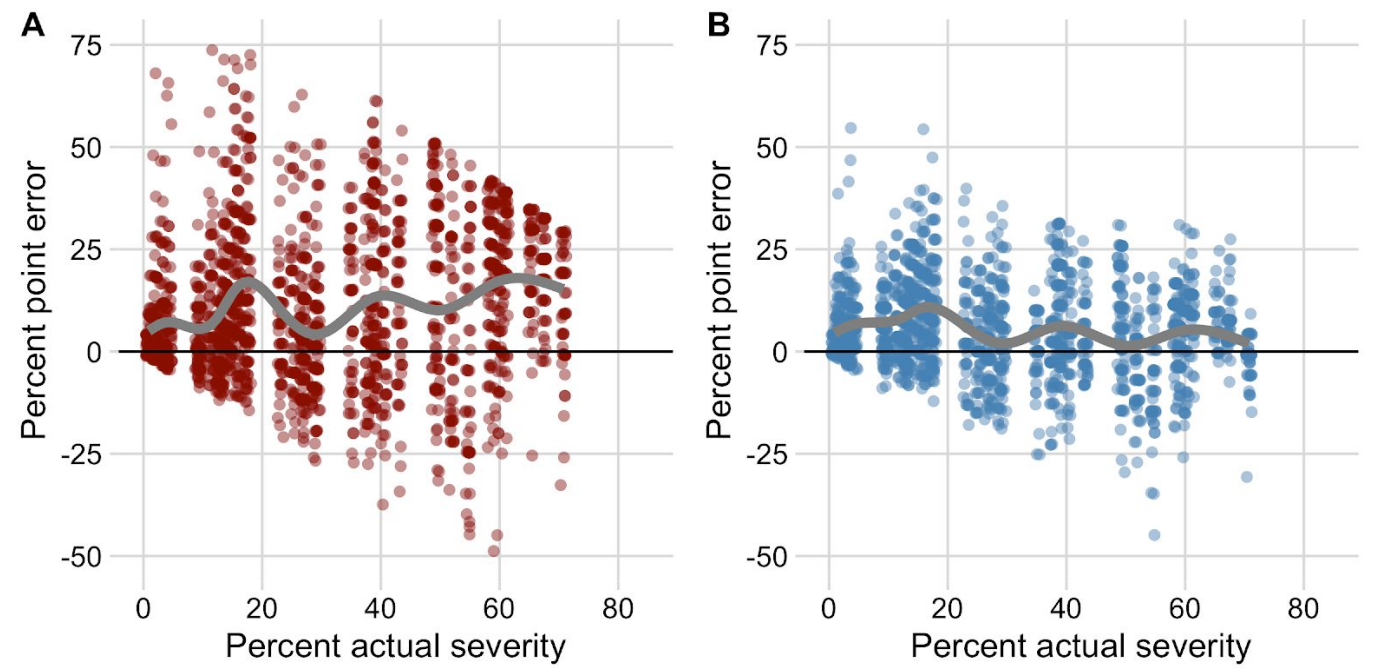

Fig. 4 Relationship between the error, expressed as the percent point difference between the estimate and actual severity value, of estimates assigned unaided (A) or aided by a standard area diagram (B) during the assessments in a sample of 40 digital images of Nicotiana tabacum leaves with symptoms caused by Xylella fastidiosa subsp. pauca by 50 raters. The dots on each plot represent 2,000 estimates (dots).

The depiction of the three CCC statistics conditioned to raters within the same Laboratory, without or with the SAD, aided in the understanding of the ramification of the errors and, consequently, of the effects (Fig. 6A). On average, the baseline (unaided estimates) accuracy was similar in most laboratories with the exception of the Laboratory $\mathrm{C}$. In the latter, the baseline accuracy was the poorest: 10 out 14 raters 
showed concordance coefficients lower than 0.7. As expected, given the upper bound of the index, raters with the poorest (best) unaided estimates benefited the most (least), with a few exceptions. There were seven raters (14\%) from three Laboratories whose overall accuracy in the unaided estimates were greater than 0.85 . When using the SAD, concordance coefficients were greater than 0.9 for 14 out of 50 raters (28\%). Losses in overall accuracy with the use of SAD were observed for five raters (10\%), two from Laboratory A and three from Laboratory B (Fig. 6B).

Table 2 Statistics of the two components of the Lin's concordance coefficient (product of generalized bias and precision) for visual estimates of severity provided unaided or with the aid of a standard area diagram (SAD) and the interrater reliability that measure the agreement between raters, both overall and grouped by laboratory (Lab.).

\begin{tabular}{|c|c|c|c|c|c|c|c|}
\hline \multirow[t]{3}{*}{ Lab. } & \multirow[t]{3}{*}{$N^{1}$} & \multicolumn{4}{|c|}{ Lin's concordance analysis components } & \multirow{2}{*}{\multicolumn{2}{|c|}{$\frac{\text { Interrater reliability }}{\operatorname{ICC}(2,1)^{3}}$}} \\
\hline & & \multicolumn{2}{|c|}{$\begin{array}{c}\text { Generalized bias } \\
\text { coefficient }^{2}\end{array}$} & \multicolumn{2}{|c|}{ Precision $^{2}$} & & \\
\hline & & Unaided & SAD & Unaided & SAD & Unaided & SAD \\
\hline A & 14 & $\begin{array}{l}0.90 \\
(0.85,0.94)\end{array}$ & $\begin{array}{l}0.93 \\
(0.90,0.97)\end{array}$ & $\begin{array}{l}0.87 \\
(0.84,0.89)\end{array}$ & $\begin{array}{l}0.90^{*} \\
(0.88,0.92)\end{array}$ & $\begin{array}{l}0.72 \\
(0.63,0.81)\end{array}$ & $\begin{array}{l}0.83 \\
(0.76,0.88)\end{array}$ \\
\hline B & 10 & $\begin{array}{l}0.89 \\
(0.83,0.94)\end{array}$ & $\begin{array}{l}0.93 \\
(0.88,0.96)\end{array}$ & $\begin{array}{l}0.89 \\
(0.86,0.92)\end{array}$ & $\begin{array}{l}0.89 \\
(0.86,0.92)\end{array}$ & $\begin{array}{l}0.74 \\
(0.63,0.83)\end{array}$ & $\begin{array}{l}0.81 \\
(0.73,0.87)\end{array}$ \\
\hline C & 14 & $\begin{array}{l}0.75 \\
(0.66,0.82)\end{array}$ & $\begin{array}{l}0.94^{\star} \\
(0.90,0.97)\end{array}$ & $\begin{array}{l}0.85 \\
(0.82,0.88)\end{array}$ & $\begin{array}{l}0.90^{*} \\
(0.88,0.92)\end{array}$ & $\begin{array}{l}0.69 \\
(0.58,0.79)\end{array}$ & $\begin{array}{l}0.79 \\
(0.70,0.86)\end{array}$ \\
\hline $\mathrm{D}$ & 12 & $\begin{array}{l}0.89 \\
(0.83,0.93)\end{array}$ & $\begin{array}{l}0.97^{\star} \\
(0.94,0.98)\end{array}$ & $\begin{array}{l}0.85 \\
(0.82,0.88)\end{array}$ & $\begin{array}{l}0.92^{*} \\
(0.90,0.94)\end{array}$ & $\begin{array}{l}0.68 \\
(0.58,0.77)\end{array}$ & $\begin{array}{l}0.86 \\
(0.81,0.90)\end{array}$ \\
\hline Overall & 50 & & & & & $\begin{array}{l}0.69 \\
(0.60,0.77)\end{array}$ & $\begin{array}{l}0.82 \\
(0.76,0.87)\end{array}$ \\
\hline
\end{tabular}

\footnotetext{
${ }^{1}$ Number of raters

${ }^{2}$ The asterisk indicates situation where the null hypothesis for the means of unaided and SAD estimates across raters within the same laboratory was rejected at $5 \%$ significance

${ }^{2}$ Following convention by Shoukri and Fleiss (1974): two-way random effects model, single rater and absolute agreement
} 


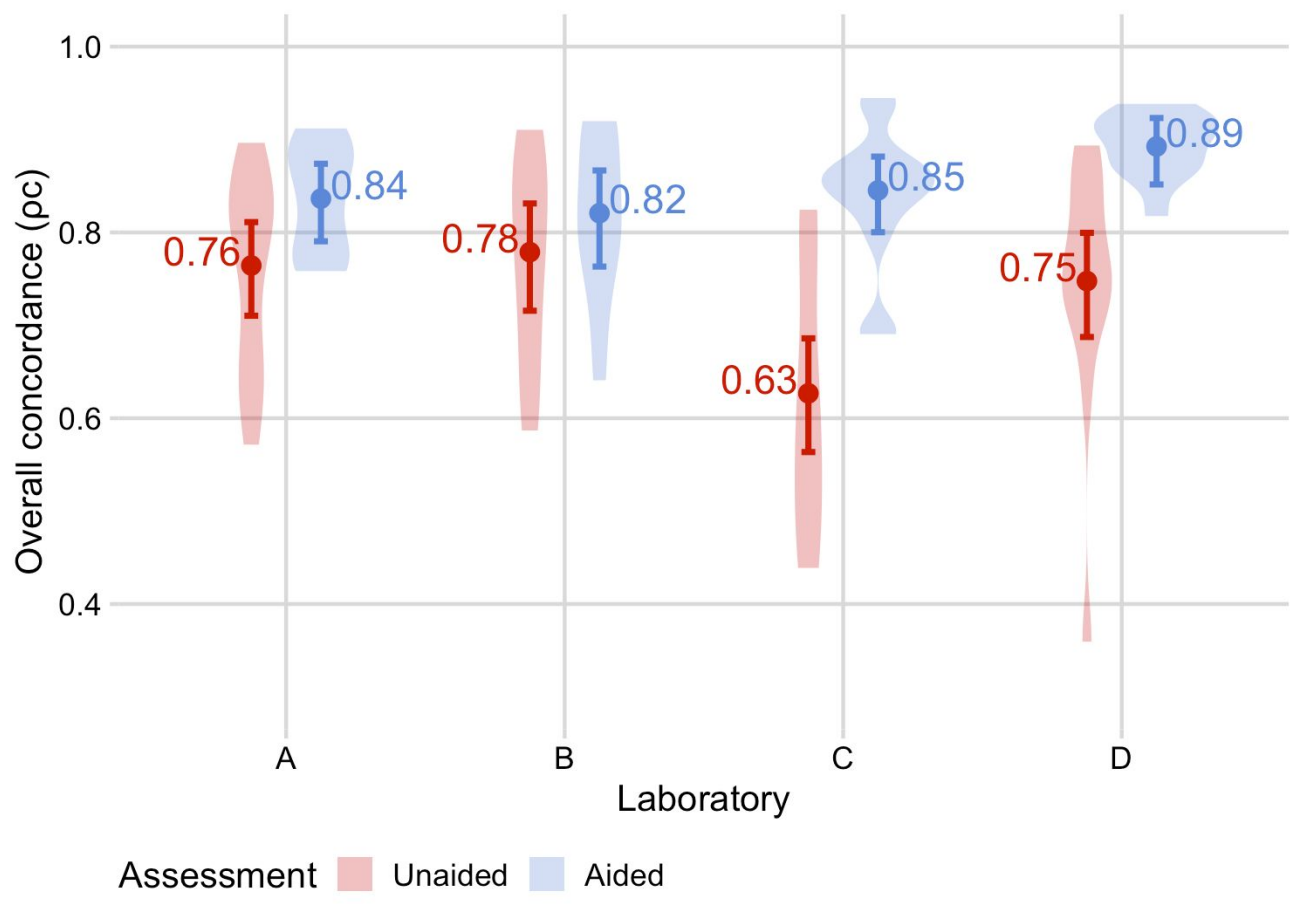

Fig. 5 Predicted marginal means and respective 95\% confidence limits of the Lin's concordance correlation coefficient by a generalized linear mixed model fitted data grouped by laboratory, here labeled A to D (check Table 1 for information on the raters). The violin plots describe the distribution of the data across the raters within each laboratory. See Table 2 for the number and characteristics of the raters.

\section{Interrater reliability}

The estimates of severity tended to be more similar between raters when using the SAD than without. For all raters combined, the overall ICC increased +0.13 (Table 2). Across the Laboratories, the ICC ranged from 0.68 to 0.74 and 0.79 to 0.83 , for the unaided and SAD-aided estimates, respectively (Table 2). 

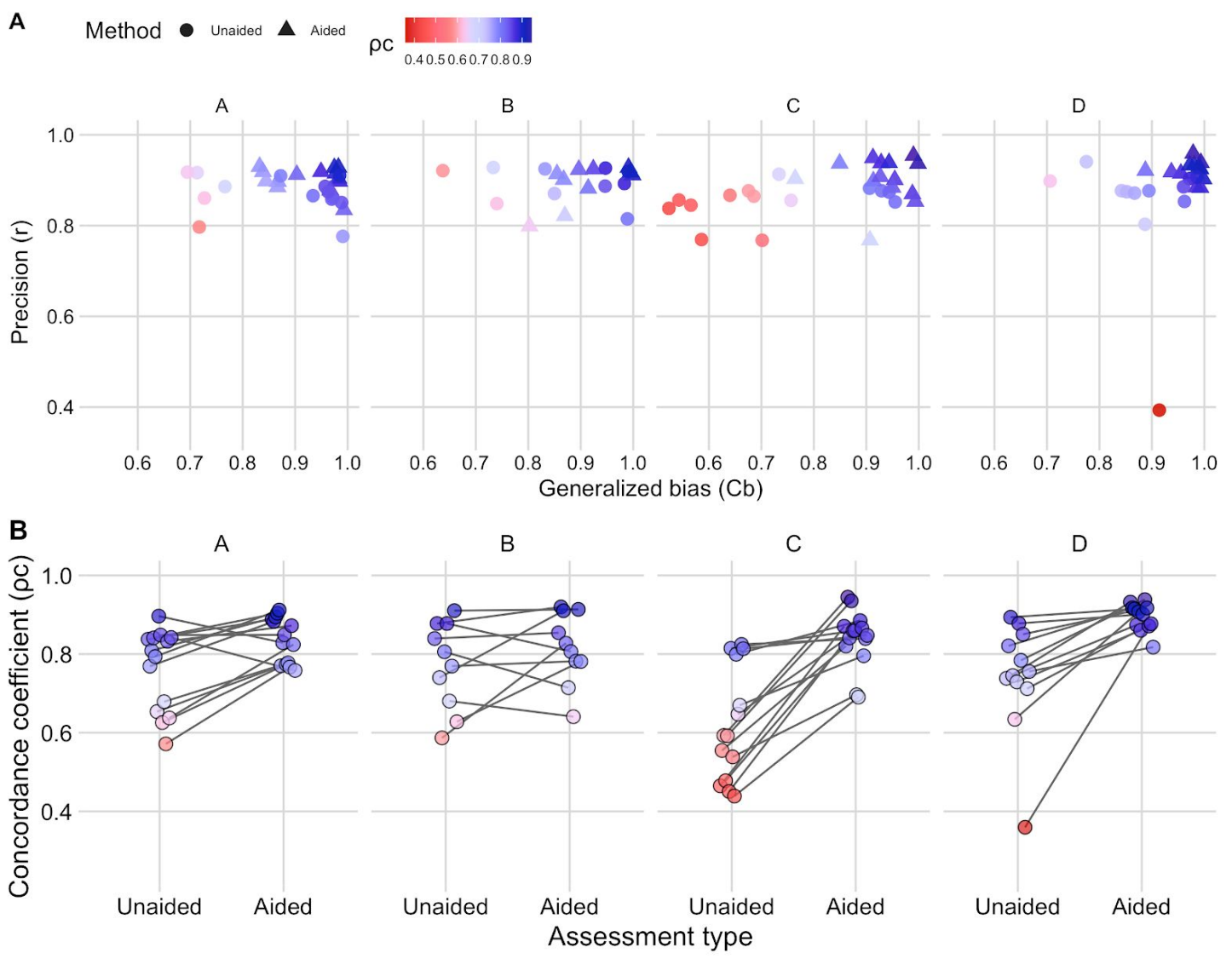

Fig. 6 A) Relationship between the two main components of the Lin's concordance correlation coefficient calculated for estimates provided unaided (filled circle) or aided (triangle) by a standard area diagram (SAD) for the severity of symptoms caused by Xylella fastidiosa subsp. pauca in Nicotiana tabacum plants. The dots in A are colored by the product of precision and generalized bias, which is the overall concordance coefficient. B) The slope graph represents the variation in the concordance coefficient among raters within the same laboratory (labeled A to D) and for a same rater at the two different assessment times, first unaided and then aided by the SAD.

\section{Discussion}

The new tool developed in this study represents an improvement in the methodology for scoring symptoms caused by X. fastidiosa subsp. pauca that are specific to tobacco plants. We used known genetic materials with regards to host susceptibility and 
pathogen aggressiveness; the tobacco cv. Havana (Francis et al. 2008; De La Fuente et al. 2013) and the 9a5c strain (Lopes et al. 2007; Muranaka et al. 2012), which are widely used in many works. However, very similar symptoms and severity were observed when using tobacco cv. RP1 (Caserta et al. 2017) and different strains of X. fastidiosa subsp. pauca, such as U24 D and 11399 (data not shown), used in other studies (Niza et al. 2016; Pierry et al. 2020). Therefore, the symptoms shown here are typical of X. fastidiosa subsp pauca, and very different from X. fastidiosa subsp. fastidiosa which have been well characterized (Francis et al. 2008).

Apart from describing and measuring the specific symptoms in inoculated tobacco plants, we found that a minimum concentration of $10^{6}$ cells $/ g$ was required for symptom expression, which reached $10^{8}$ cells/g at 80 DAI, remaining constant in the following 40 days. This trend was similar to that reported by De La Fuente et al. (2013) using X. fastidiosa subsp fastidiosa "Temecula" strain that causes Pierce Disease in grape. The minimal concentration we observed here was 10 times lower than that for Citrus sinensis (Almeida et al. 2001), highlighting the high susceptibility of tobacco to X. fastidiosa subsp. pauca.

In our previous studies we have adapted a disease rating system developed for scoring severity X.fastidiosa subsp. pauca-induced symptoms on citrus leaves (Amorim et al. 1993; Muranaka et al. 2013; Caserta et al. 2017). Although the original SAD for CVC (Amorim et al. 1993) was meant to aid in the estimation of percent severity, the visual ratings on tobacco and citrus have been based on a hybrid system of six ordinal scores (percent intervals) defined based on the Horsfall-Barratt $(\mathrm{H}-\mathrm{B})$ scale supported with diagrammatic representations of citrus leaves (Muranaka et al. 2013; Caserta et al. 2017). Although convenient, there are drawbacks to using the $\mathrm{H}-\mathrm{B}$ scale associated with risk of errors and wrong decisions (Bock et al. 2015; Chiang et al. 2016; Del Ponte et al. 2019) as 
well as with the analyses of ordinal data, white require special care during the analysis (Shah and Madden 2004; Chiang et al. 2017). As far as severity of foliar disease is concerned, direct estimates of percent severity are more informative as long as they are sufficiently accurate, a condition that is not always possible given the subjectiveness of the task when human raters are employed.

The actual severity in this study resulted from the combination of three measures obtained by the different software, which were in strong agreement between each other. The values differed slightly between depending on the leaf - see example for image 26 of the validation set in Supplemental Fig. 2. The use of a single measure by each software as actual value did not affect the results and the estimates were very similar in magnitude (data not shown). The APS Assess (Lamari 2009) is probably the most used and trustworthy software in phytopathometry, together with Quant (Vale et al. 2003) (discontinued and of limited availability) (Del Ponte et al. 2017). A drawback to many potential users may be the relatively high costs for licensing APS Assess. Between the two free alternatives tested in our study, which have seldom being used in SAD research, Leaf Doctor was very easy to use and also quicker ( 40 s) than ImageJ ( 60 s) and Assess ( 100s) for the conditions evaluated in our study, which were images pre-processed for standardizing background. Although a plethora of software has been used to determine actual severity (Del Ponte et al. 2017), comparison among the different softwares are not often an objective in SAD studies. Variability in severity measurements on a same specimen when different software or raters have been reported (Bock et al. 2008; Melo et al. 2020). Therefore, any of the softwares tested here can be used if the conditions are the same, especially if one trained operator is thresholding the images.

Assessing percent severity visually, depending on the objective and scale, is a more time and cost effective method but the quality of the estimates depends heavily on 
a number of factors among which the rater's ability plays an important role together with symptomatic patterns (Bock et al. 2016). Overall, rater's estimates in our study were closer to the actual value and they tended to agree more with each other when using the SAD compared with unaided estimates. This result is in general agreement with more than one hundred SAD validation studies (Del Ponte et al. 2017). However, for most of the raters in our relatively large sample of 50 raters, the index of concordance was below 0.90 when using the SAD. It is possible that the specific symptomatic pattern in the studied pathosystem are not as easy to discern as it is in citrus colonized by X. fastidiosa subsp. pauca. In both plants, they tend to prevail in the outer margin of the leaves, but the size, color and shape are quite distinct, being much less conspicuous and more numerous in tobacco than in citrus. The specific symptoms may in part explain in part why the the global average of the Lin's concordance coefficients greater than 0.9. In fact, this is not uncommon in SAD validation studies that used the Lin's CCC for summarizing accuracy and precision (Yadav et al. 2013; Braido et al. 2014; Schwank and Del Ponte 2014; Dolinski et al. 2017; Araujo et al. 2019; Mello et al. 2020, Sterling et al. 2020). However, the reasons for not reaching means of Lin's CCC $>0.9$ can be of various nature, a topic worth of further exploration.

Previous studies on SADs for several other diseases have shown that errors are frequently large, especially at the lower end $(<15 \%)$ for those in which the symptoms are comprised of small and numerous lesions scattered across the leaf (Bock et al. 2020). This pattern was quite evident in this study even using four reference diagrams from minimum to $15 \%$ severity. In the study by Amorim et al. (1993) the estimates of CVC severity on 82 citrus leaves were obtained only aided by two versions of an SAD. Best results were obtained with the second version in which the maximum value was reduced from 64 to $56 \%$ and an additional reference was placed between 25 and $56 \%$ severity. 
The average precision $(r)$ calculated for three raters was 0.93 , which was slightly better than the overall mean $r$ found in our study 0.90 when using the aid. In fact, the index of agreement from the first (unaided) assessment in this study was, on average, equal or lower than 0.78 across raters. Descriptive scales to classify the strength of agreement for CCC index (or ICC, when equivalent) values have been proposed but they are arbitrary and context-dependent (Koo and Li 2015, Perinetti 2018). Further studies in this area will be important to investigate whether a universal threshold for the CCC should be adopted when judging the value of the SADs.

Although a significant improvement was observed overall, a few raters were capable of providing SAD-aided estimates that were poorer than the unaided ones. It is expected that for raters whose estimates are innately very accurate, the SADs usually have little positive effect, if any. In some occasions the use of the SAD can be detrimental as shown in regression plots between gain/loss from using the SAD and unaided estimates (González-Domínguez et al. 2014; Franceschi et al. 2020; Mello et al. 2020). This kind of response is not understood or easy to explain as they may be due to random error or specific test conditions. In our study, not all raters whose accuracy of the estimates decreased when using the SAD were innately capable of providing accurate estimates with no aid. In fact, they composed $10 \%$ of the raters, selected in two Laboratories. This explains the little or no effect on the means of agreement in two Laboratories. The reasons for the discrepancies among the Laboratories are not too evident considering the similarity in the test conditions. It is possible that individual rather than the test-related factors were of more influence in the results. In the only study in which a multi-laboratory SAD validation was performed, the discrepancies in the results between the two laboratories were deemed to have been influenced by different test conditions such as instructions and the actual values determined using 
different software by different person on each Laboratory (Melo et al. 2020). Here, we used a common set of slides with written instructions and the same set of images with severity measured by the same person and software for validation. The profile of the raters were somewhat different between the Laboratories. In the Laboratory B where most the use of the SAD was more detrimental, the group was most represented by undergraduate students not used to recognise disease symptoms, but the unaided estimates were, on average, numerically higher than the other Laboratories. On the other hand, in two Laboratories ( $C$ and $D)$ with the higher overall increase in concordance, the groups was composed of graduate students in plant pathology who are more aware of how to use SADs for other diseases, so that the instructions were better interpreted. Again, it is not easy to understand the exact reasons given the subjectiveness of the task. Nevertheless, our results corroborate the findings by Mello et al. (2020) who also found only numerical improvement in concordance from using the SAD by raters from one laboratory, while significant improvement was found in the other Laboratory. Finally, we also found that the inter-rater reliability increased when using the $\mathrm{SAD}$, further demonstrating that the $\mathrm{SAD}$ developed and validated in this work might be a useful tool to accelerate the studies regarding X. fastidiosa-plant interaction.

\section{Acknowledgements}

We thank Luis F. C. da Silva for his assistance in greenhouse plant propagation. This work was supported by research grants from Fundação de Amparo à Pesquisa do Estado de São Paulo (FAPESP -2013/10957-0) and Conselho Nacional de Desenvolvimento Científico e Tecnológico (INCT - Citros Proc. CNPQ 465440/2014-2 and FAPESP 2014/50880-0). WEL Pereira was a fellow MSc and PhD from FAPESP (2011/14629-2 and 
2016/01273-9). EM Del Ponte, MA Takita, HD Coletta-Filho and AA de Souza are recipients of research fellowships from CNPq. We are thankful for the students, postdocs and researchers who participated in the experiments for the validation of the new tool.

\section{Conflict of interests}

The authors declare that they have no known competing financial interests or personal relationships that could have appeared to influence the work reported in this paper.

\section{Author's contribution}

WEL Pereira and SMP Andrade conducted the experiments and statistical analysis. MB Esteves and MC Canale conducted experiments. EM Del Ponte advised on data analysis, prepared graphs and wrote the manuscript. AA de Souza conceptualized the work and wrote the manuscript. HD Coletta-Filho and MA Takita discussed the data.

\section{Data availability statement}

The data and scripts for performing the analysis and produce the graphs are publicly available as research compendium at https://osf.io.... The data are stored as text files and the R codes were prepared as RMarkdown documents. Webpages were produced to facilitate navigating through the commented scripts and outcomes. 


\section{References}

Almeida RPP, Pereira, EF, Purcell AH, Lopes JRS (2001) Multiplication and movement of a citrus strain of Xylella fastidiosa within sweet orange. Plant Disease 85:382-386

Almeida RPP, De La Fuente L, Koebnik R, Lopes JRS, Parnell S, Scherm H (2019) Addressing the new global threat of Xylella fastidiosa. Phytopathology 109:172-174

Alves E, Kitajima EW, Leite B (2003) Interaction of Xylella fastidiosa with different cultivars of nicotiana tabacum: a comparison of colonization patterns. Journal of Phytopathology 151:500-506

Amorim L, Bergamin Filho A, Palazzo D, Bassanezi RB, Godoy CV, Torres GAM (1993) Citrus variegated chlorosis: a diagrammatic scale for assessment of disease severity. Fitopatologia Brasileira 18:174-180

Andreote FD, Lacava PT, Gai CS, Araújo WL, Maccheroni W, Overbeek LS Van, Elsas JD Van (2006) Model plants for studying the interaction between Methylobacterium mesophilicum and Xylella fastidiosa. Canadian Journal of Microbiology 52:419-426

Araújo ER, Resende RS, Krezanoski CE, Duarte HS (2019) A standard area diagram set for severity assessment of botrytis leaf blight of onion. European Journal of Plant Pathology 153:273-277

Barnhart HX, Haber M, Song J (2002) Overall concordance correlation coefficient for evaluating agreement among multiple observers. Biometrics 58:1020-1027

Barnhart HX, Haber M, Lin LI (2007) An overview on assessing agreement with continuous measurements. Journal of Biopharmaceutical Statistics 17:529-569

Bock CH, Parker PE, Cook AZ, Gottwald TR (2008) Visual assessment and the use of image analysis for assessing different symptoms of citrus canker on grapefruit leaves. Plant Disease 92:530-541

Bock CH, Poole GH, Parker PE, Gottwald TR (2010) Plant disease severity estimated visually, by digital photography and image analysis, and by hyperspectral imaging. Critical Reviews in Plant Sciences 29:59-107

Bock CH, Chiang K, Del Ponte EM (2016) Accuracy of plant specimen disease severity estimates: concepts, history, methods, ramifications and challenges for the future. $\mathrm{CAB}$ Reviews 11: 1-21

Bock CH, Barbedo JG, Del Ponte EM, Bohnenkamp D, Mahlein AK (2020) From visual estimates to fully automated sensor-based measurements of plant disease severity: status and challenges for improving accuracy. Phytopathology Research 2: 1-30

Braido R, Goncalves-Zuliani AMO, Janeiro V, Carvalho SA, Belasque Junior J, Bock CH, Nunes WMC (2014) Development and validation of standard area diagrams as assessment aids for estimating the severity of citrus canker on unripe oranges. Plant Disease 98:1543-1550 
Brooks ME, Kristensen K, van Benthem KJ, Magnusson A, Berg CW, Nielsen A, Skaug HJ, Maechler M, Bolker BM (2017) glmmTMB balances speed and flexibility among packages for zero-inflated generalized linear mixed modeling. The R Journal, 9:378-400

Caserta R, Souza-Neto RR, Takita MA, Lindow SE, De Souza AA (2017) Ectopic expression of Xylella fastidiosa rpfF conferring production of diffusible signal factor in transgenic tobacco and citrus alters pathogen behavior and reduces disease severity. Molecular Plant-Microbe Interactions 30:866-875

Chang CJ, Garnier M, Zreik L, Rossetti V, Bové JM (1993) Culture and serological detection of the xylem-limited bacterium causing variegated chlorosis and its identification as a strain of Xylella fastidiosa. Current Microbiology 27:137-142

Chiang KS, Bock CH, El Jarroudi M, Delfosse P, Lee IH, Liu HI (2016) Effects of rater bias and assessment method on disease severity estimation with regard to hypothesis testing. Plant Pathology 65:523-535

Chiang KS, Liu HI, Tsa, JW, Tsai JR, Bock CH (2017) A discussion on disease severity index values. Part II: using the disease severity index for null hypothesis testing. Annals of Applied Biology 171:490-505

Coletta-Filho HD, Gonçalves FP, Amorim, L, De Souza AA, Machado MA (2013) Survey of Xylella fastidiosa and citrus Variegated Chlorosis in São Paulo State, Brazil. Journal of Plant Pathology 1:12-18

Coletta-Filho HD, Castillo AI, Laranjeira FF, Andrade EC, Silva NT, Souza AA, Bossi ME, Lopes JRS (2020) Citrus Variegated Chlorosis: an overview of 30 years of research and disease management. Online: https://doi.org/10.1007/s40858-020-00358-5

Damsteegt VD, Brlansky RH, Phillips PA, Roy A (2006) Transmission of Xylella fastidiosa, causal agent of Citrus Variegated Chlorosis, by the glassy-winged sharpshooter, Homalodisca coagulata. Plant Disease 90:567-570

Dandekar AM, Gouran H, Ibáñez AM, Uratsu SL, Agüero CB, McFarland S, Borhani Y, Feldstein PA, Bruening G, Nascimento R, Goulart LR, Pardington PE, Chaudhary A, Norvell M, Civerolo E, Gupta G (2012) An engineered innate immune defense protects grapevines from Pierce disease. Proceedings of the National Academy of Sciences of the United States of America 109:3721-3725

Davis MJ, French WJ, Schaad NW (1981) Axenic culture of the bacteria associated with phony disease of peach and plum leaf scald. Current Microbiology 5:311-316

De La Fuente L, Parker JK, Oliver JE, Granger S, Brannen PM, van Santen E, Cobine PA (2013) The bacterial pathogen Xylella fastidiosa affects the leaf ionome of plant hosts during infection. PLoS One 8:1-9

Del Ponte EM, Pethybridge SJ, Bock CH, Michereff SJ, Machado FJ, Spolti P (2017) Standard area diagrams for aiding severity estimation: scientometrics, pathosystems, and methodological trends in the last 25 years. Phytopathology 107:1161-1174

Del Ponte EM, Nelson SC, Pethybridge SJ (2019) Evaluation of app-embedded disease scales for aiding visual severity estimation of Cercospora leaf spot of table beet. Plant Disease 103:1347-1356 
Dolinski MA, Duarte HDSS, Silva JB, May De Mio LL (2017). Development and validation of a standard area diagram set for assessment of peach rust. European Journal of Plant Pathology 148:817-824

Franceschi VT, Alves KS, Mazaro SM, Godoy CV, Duarte HS, Del Ponte EM (2020) A new standard area diagram set for assessment of severity of soybean rust improves accuracy of estimates and optimizes resource use. Plant Pathology 69:495-505

Francis M, Civerolo EL, Bruening G (2008) Improved bioassay of Xylella fastidiosa using Nicotiana tabacum cultivar SR1. Plant Disease 92:14-20

Gamer M, Lemon J, Singh IFP (2019). irr: various coefficients of interrater reliability and agreement. R package version 0.84.1. https://CRAN.R-project.org/package=irr

Hill BL, Purcell AH (1995) Acquisition and retention of Xylella fastidiosa by an efficient vector, Graphocephala atropunctata. Phytopathology 85: 209-212

Koo TK, Li MY (2016) A guideline of selecting and reporting intraclass correlation coefficients for reliability research. Journal of Chiropractic Medicine 15:155-163

Lamari L (2009). Assess: image analysis software for plant disease quantification V2.0. The American Phytopathological Society, St Paul.

Liu HI, Tsai JR, Chung WH, Bock CH, Chiang KS (2019). Effects of quantitative ordinal scale design on the accuracy of estimates of mean disease severity. Agronomy 9:565.

Lopes SA, Ribeiro DM, Roberto PG, França SC, Santos JM (2000) Nicotiana tabacum as an experimental host for the study of plant - Xylella fastidiosa interactions. Plant Disease 84:827-830

Lopes SA, Teixeira DC, Fernandes NG, Ayres AJ, Torres SCZ, Barbosa JC, Li WB (2007) An experimental inoculation system to study citrus - Xylella fastidiosa interactions. Plant Disease 89:250-254

Lopes SA, Raiol Jr LL, Torres SC, Martins EC, Prado SS, Beriam LO (2019) Differential responses of tobacco to the citrus variegated chlorosis and coffee stem atrophy strains of Xylella fastidiosa. Phytopathology 110:567-573

Lucas JA (2020) Plant pathology and plant pathogens. John Wiley \& Sons.

Madden LV, Hughes G, Van Den Bosch F (2007) The Study of Plant Disease Epidemics. American Phytopathological Society Press

Mansfield J, Genin S, Magori S, Citovsky V, Sriariyanum M, Ronald P, Dow M, Verdier V, Beer SV, Machado M A, Toth IAN, Salmond G, Foster GD, Lipm IP, Tolosan FC (2012) Top 10 plant pathogenic bacteria in molecular plant pathology. Molecular Plant Pathology 13:614-629

Melo VP, Mendonça ACS, Souza HS, Gabriel LC, Bock CH, Eaton MJ, Schwan-Estrada KR, Nunes WMC (2020) Reproducibility of the development and validation process of standard area diagram by two laboratories: An example using the Botrytis cinerea/Gerbera jamesonii pathosystem. Plant disease. Online at: https://doi.org/10.1094/PDIS-08-19-1708-RE 
Muranaka LS, Giorgiano TE, Takita MA, Forim MR, Silva LF, Coletta-Filho HD, Machado MA, de Souza AA 2013 N-acetylcysteine in agriculture, a novel use for an old molecule: focus on controlling the plant-pathogen Xylella fastidiosa. PLoS One 23;8(8):e72937

Murray MG, Thompson WF (1980) Rapid isolation of high molecular weight plant DNA. Nucleic Acids Research 8:4321-4325

Niza B, Merfa MV, Alencar VC, Menegidio FB, Nunes LR, Machado MA, Takita MA, Souza AA (2016) Draft genome sequence of 11399, a transformable citrus-pathogenic strain of Xylella fastidiosa. Genome Announcements 4:e01124-16. doi:10.1128/genomeA.01124-16

Nutter FW, Esker PD, Netto RAC (2006) Disease assessment concepts and the advancements made in improving the accuracy and precision of plant disease data. European Journal of Plant Pathology 115:95-103

Oliveira AC, Vallim MA, Semighini CP, Araújo WL, Goldman GH, Machado MA (2002) Quantification of Xylella fastidiosa from citrus trees by real-time polymerase chain reaction assay. Phytopathology 92:1048-1054

Pethybridge SJ, Nelson SC (2015) Leaf Doctor: A new portable application for quantifying plant disease severity. Plant disease 99:1310-1316

Pierry PM, de Santana WO, Kitajima JP, et al. (2020) High-quality draft genome sequence resources of eight Xylella fastidiosa strains isolated from citrus, coffee, plum and hibiscus in South America. Phytopathology. doi:10.1094/PHYTO-05-20-0162-A

Perinetti G (2018). StaTips Part IV: Selection, interpretation and reporting of the intraclass correlation coefficient. South European Journal of Orthodontics and Dentofacial Research 5:3-5

Shah DA, Madden LV (2004) Nonparametric analysis of ordinal data in designed factorial experiments. Phytopathology 94:33-43

Saponari M, Boscia D, Nigro F, Martelli GP (2013) Identification of DNA sequences related to Xylella fastidiosa in oleander, almond and olive trees exhibiting leaf scorch symptoms in Apulia (Southern Italy). Journal of Plant Pathology 95:668

Schwanck AA, Del Ponte EM (2014) Accuracy and reliability of severity estimates using linear or logarithmic disease diagram sets in true colour or black and white: a study case for rice brown spot. Journal of Phytopathology 162:670-682

Schneider CA, Rasband WS, Eliceiri KW (2012) NIH Image to ImageJ: 25 years of image analysis. Nature methods, 9:671-675

Shrout PE, Fleiss J (1979). Intraclass correlations: Uses in assessing rater reliability. Psychological Bulletin 86:420-428

Sterling A, Gómez-Torres, AK, Suárez-Córdoba YD, Loaiza-Molina LC, Sierra-Hayer JF (2020) Standard area diagrams to assess black crust (Phyllachora huberi) severity on rubber tree leaflets. European Journal of Plant Pathology 156:827-837.

Stevenson M, Nunes T, Heuer C, Marshall J, Sanchez J, Thornton R, Reiczigel J, Robinson-Cox J, Sebastiani P, Solymos P, Yoshida K, Jones G, Pirikahu, Firestone S, Kyle 
R, Popp J, Jay M, Reynard C (2019) epiR: Tools for the Analysis of Epidemiological Data. R package version 1.0-4. https://CRAN.R-project.org/package=epiR

Vale FXR, Fernandes Filho EI, Liberato JR (2003) QUANT: a software for plant disease severity assessment. In: Close R, Braithwaite M, Havery I (Eds.) Proceedings of the 8th International Congress of Plant Pathology. pp. 105

Yadav NVS, de Vos SM, Bock CH, Wood BW (2013) Development and validation of standard area diagrams to aid assessment of pecan scab symptoms on pecan fruit. Plant Pathology 62:325-335 

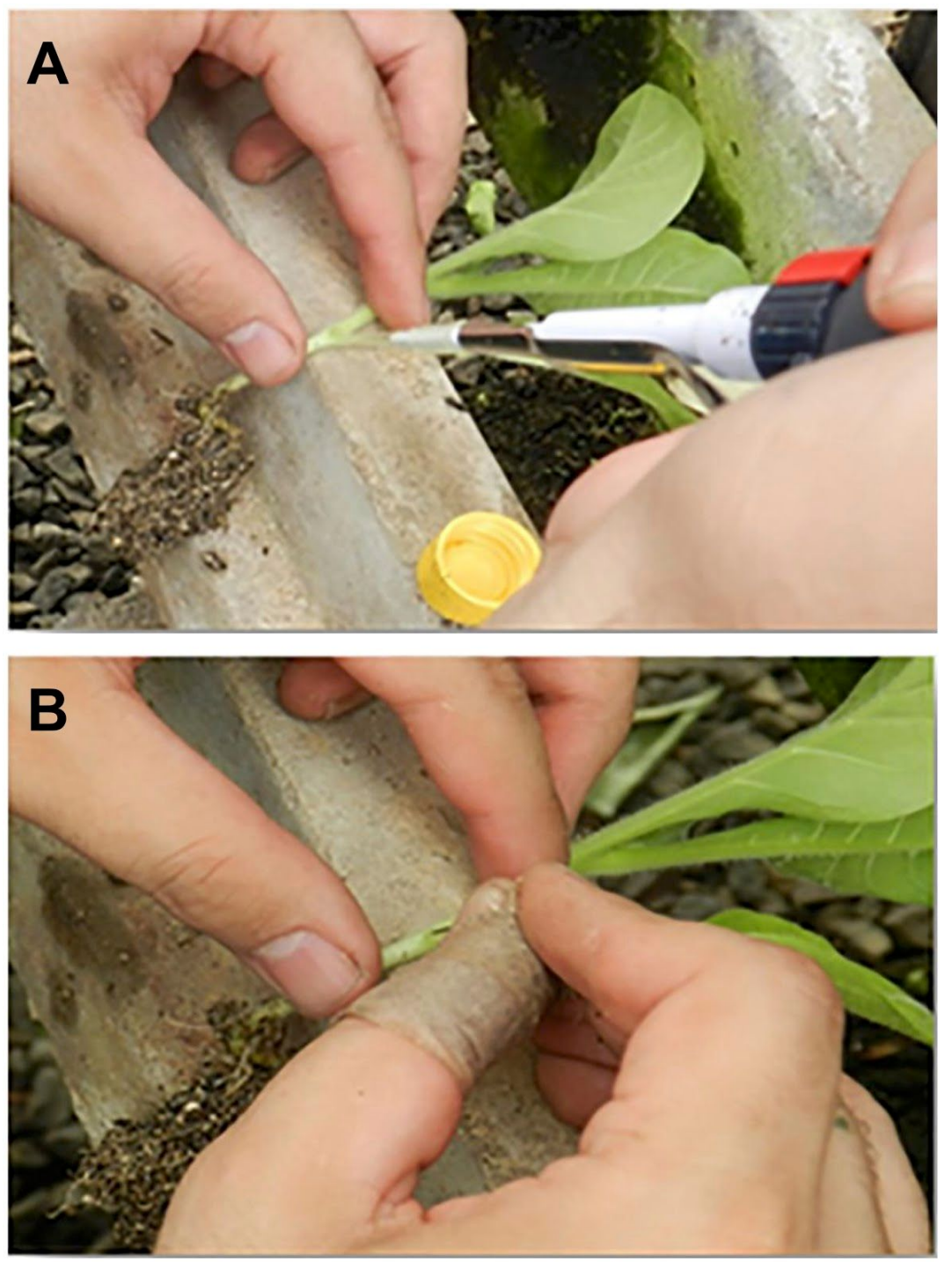

Suppl. Figure 1. Detailed view of the inoculation of Xylella fastidiosa subsp. pauca at the base of five-day old Nicotiana tabacum plants 


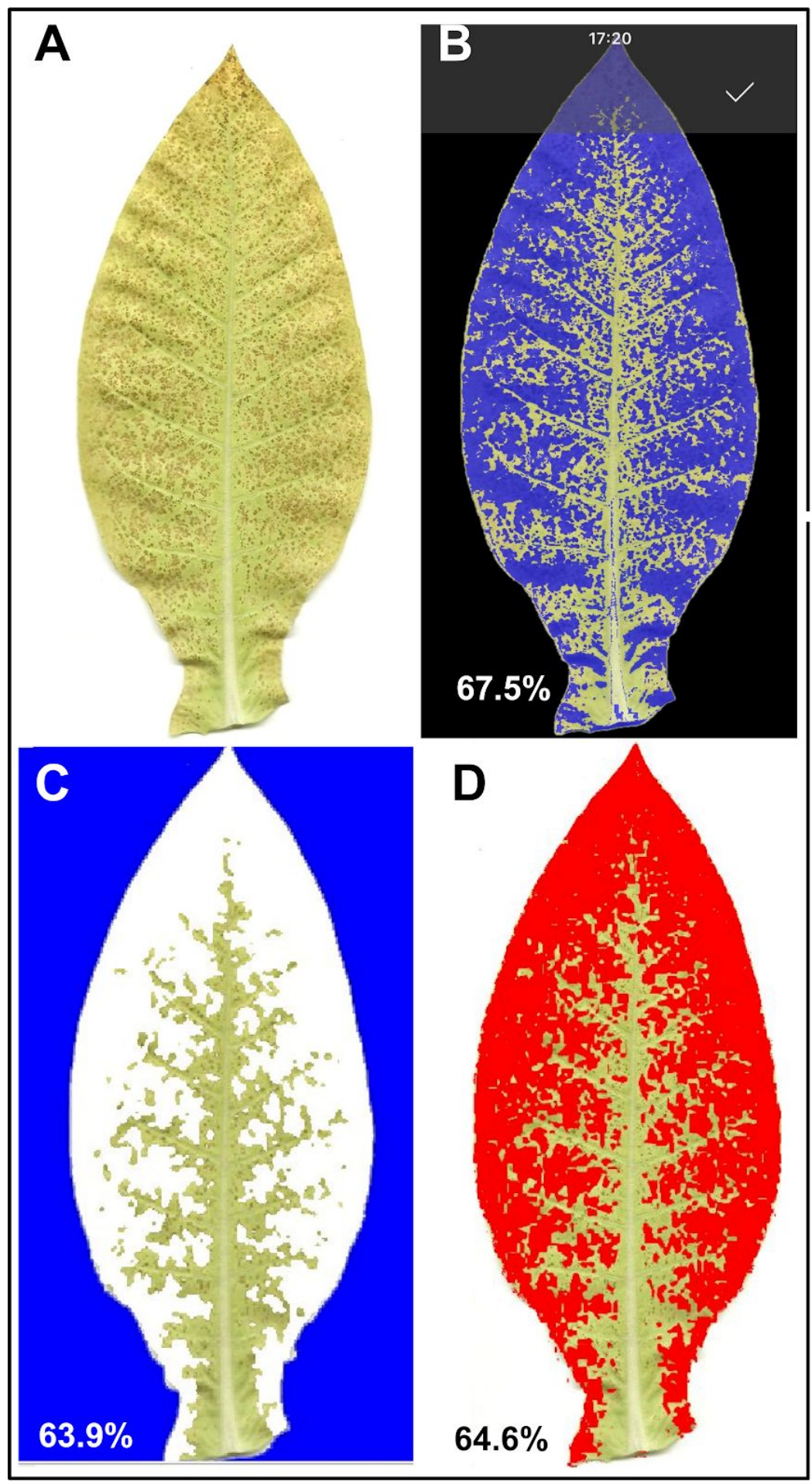

Suppl. Figure 1. Example of a Nicotiana tabacum leaf (A) displaying symptoms of Xylella fastidiosa subsp. pauca after inoculation at the base of five-day old plants. The segmentation and calculation of severity (percent area affected) were made manually by the same operator using Leaf Doctor (B) APS Assess (C) or ImageJ (D) image analysis softwares. 